\title{
trabahonecessário
}

issn: $1808-799 \mathrm{X}$

ano 3 número $3-2005$

\section{EMPRESÁRIOS E GOVERNO NO ESTADO DA BAHIA: \\ em direção a uma sociedade mais competitiva}

Cristiano Lima Ferraz[1]

\section{Introdução}

A realização de mudanças político-institucionais, sócio-econômicas e culturais, visando a elevação da competitividade social nos marcos do ethos empresarial, vem sendo a bandeira de luta da burguesia industrial no Brasil durante as duas últimas décadas[2]. A estruturação das instituições públicas e dos vários espaços de sociabilidade com base nesses fundamentos, bem como a privatização do fundo público, resultaria na construção do que seria, na nossa opinião, a Sociedade Competitiva - aqui um desdobramento a partir do modelo teórico desenvolvido por Rodrigues[3]. Para o empresariado, a materialização dessa realidade seria um requisito indispensável para consolidar modificações nas bases de acumulação do bloco histórico americanista[4], estruturadas pelo regime de acumulação fordista. Hegemônicas em nível mundial no II Pós Guerra, as bases de acumulação do americanismo se encontram abaladas desde finais dos anos 60 no núcleo orgânico do capitalismo mundial, sofrendo ali transformações importantes a partir dos anos 70. No Brasil, essas mudanças são percebidas mais claramente no decorrer da década de 80, sendo mais expressivas nos anos 90. Delineia-se então um quadro de transformações na organização da produção social da vida[5], que se expressa como um complexo de relações econômicas, ético-políticas e tecno-científicas presentes, tanto nos processos produtivos, na qualificação da força de trabalho e nas formas atuais de sociabilidade, quanto no Estado estrito senso, particularmente no que se refere às suas formas de atuação frente à sociedade. No trabalho que dá origem a esse artigo investigamos essas mudanças a partir da realidade baiana, tendo em vista as mediações do Estado, da Produção e da Formação Humana que, em uma relação sintética, apontaria 
ali para uma metamorfose no industrialismo americanista[6].

Analisaremos neste artigo um dos aspectos dessa trama: a relação entre Governo e Capital nas transformações do Estado e do modelo de desenvolvimento na Bahia. Tal relação constitui fundamento empírico e analítico necessário para entender o movimento atual de relocalização industrial que, por sua vez, vem contribuindo, no cenário baiano, para a reestruturação produtiva de empresas oriundas do Centro-Sul que buscam elevar sua competitividade na fase atual do capitalismo. Contribui também para entender o surgimento de novos segmentos operários no Brasil, trabalhadores estes que, no contexto da relocalização industrial e por conta do próprio caráter da atual reestruturação produtiva, vêm sendo objeto de novas estratégias qualificação, pautadas pela efemeridade e flexibilidade, quando a formação humana se torna cada vez mais à imagem e semelhança do próprio Capital, contribuindo ainda para isso o fato de estar sendo atravessada por conteúdos ético-políticos vinculados ao ethos empresarial em detrimento do ethos do Trabalho, não se perdendo de vista as contradições que isso suscita[7]. Enfim, a relação que aqui focalizaremos contribui para entender como os empresários e Governo tentam pavimentar, no Estado da Bahia, o caminho em direção à Sociedade Competitiva.

\section{Reformas e Desenvolvimento: a burguesia industrial definindo um caminho}

Desde o inicio dos anos 80, no momento em que ocorria no país a "abertura" política e econômica, a linha política traçada para o desenvolvimento econômico na Bahia previa a tentativa de diversificação da industria local, historicamente concentrada na produção de bens intermediários nos setor químico, petroquímico, siderúrgico e metal-mecânico.

Segundo o Governo[8], essa concentração prejudicava a competitividade estadual naquele novo cenário. A meta era também estimular e desenvolver atividades industriais com maior valor agregado, como a produção de bens de consumo final, de modo que o Estado captasse melhores vantagens nas relações de troca nacionais. Para isso o poder público baiano exigia um tratamento diferenciado por parte do Governo Federal - esse era um discurso recorrente. Já em 1983, Orlando Moscozo, então presidente da Federação das Indústrias do Estado da Bahia - FIEB, mostrava a necessidade de uma maior diversificação da base produtiva na Bahia. Sinalizava ainda insatisfação com a correlação de forças entre o Centro-Sul e o Nordeste, pois, os "Estados fortes (...) ainda sugam os mais fracos", havendo "uma exploração colonial, por parte dos Estados mais fortes, dos Estados mais fracos [sic]" [9]. Para Moscozo, era necessária uma maior articulação das elites empresariais nordestinas em torno de objetivos comuns, firmando uma atitude mais 
propositiva frente ao Estado, bem como uma política mais ativa do Governo estadual no fomento ao desenvolvimento regional[10]. Reivindicava também uma maior participação da burguesia industrial no Governo Estadual o que, segundo ele, era dificultado, inclusive, pela forma de atuação do empresariado, que não costumava se mobilizar e participar politicamente para defender seus interesses junto à aparelhagem estatal. Mas, segundo Moscozo, operava-se uma mudança:

É que está vindo uma turma nova, uma turma jovem, que está se preparando, estudando. Esse pessoal novo está mudando a mentalidade dos mais velhos e, ao mesmo tempo, assumindo o comando. (...). O empresariado está querendo preparar-se para poder integrar-se com um governo que seja escolhido no Brasil, para ajudar o governo, ajudar a Nação e, em conseqüência ajudar o seu próprio negócio.[11]

A burguesia industrial revelava interesse crescente em modificar a institucionalidade do Estado, fazendo avançar naquele espaço a cultura empresarial-privatista. Tinha clareza de que para concretizar esse objetivo precisaria se "instrumentalizar" melhor. Previa também que, para alcançar seu intento, seria fundamental uma maior interação do empresariado junto à aparelhagem estatal. Porém, nos anos 80, não havia ainda uma maior sintonia entre Governo e empresários no Estado da Bahia, no que se trata da elaboração de uma agenda político-econômica e institucional afinada com as demandas que se apresentavam para o Capital[12]. De todo modo, o empresariado se articulava em torno de seus interesses do momento. No final dos anos 80 já discutia, inclusive com o Governo, uma nova proposta de desenvolvimento industrial. Na ocasião Moscozo advertia que

O processo moderno de industrialização da Bahia não pode se desvincular do panorama regional e mesmo nacional, razão pela qual a política industrial deve levar em conta esse fato. Existe, a nível nacional [sic], o consenso de que a política industrial brasileira deve ser repensada a partir do esgotamento do chamado "modelo de substituição das importações". (...) A Bahia, mais do que qualquer outro Estado deve repensar seu modelo de desenvolvimento industrial e estabelecer novas diretrizes de política. A Bahia já está em patamar que requer novas opções e, para tanto, esforço político é indispensável ao encontro de caminhos alternativos para o seu processo de industrialização[13] [grifo nosso].

Tendo em vista o cenário que se desenhava no âmbito do Governo Federal, as reivindicações da burguesia industrial local frente ao Governo Estadual delineariam o que parece ser a particularidade da metamorfose do industrialismo na Bahia, pautada por uma versão neodesenvolvimentista, ao mesmo tempo em que permeada por um movimento 
mais total de desconstrução do ethos público na aparelhagem estatal, a exemplo do que ocorria em nível federal.

\section{Lançando as Bases das Reformas}

A estratégia do empresariado começa a surtir efeito a partir de 1991, quando Antônio Carlos Magalhães assume o Governo, recolocando o Partido da Frente Liberal - PFL no comando do poder, após uma fase em que a administração estadual iniciada por Waldir Pires e concluída por Nilo Coelho, era hegemonizada pelo Partido do Movimento Democrata Brasileiro - PMDB. ACM sinalizava como ponto negativo da administração anterior a falta de uma política de desenvolvimento. Essa ausência seria suprida pelo Programa de Promoção do Desenvolvimento da Bahia - PROBAHIA, lançado em 31/10/1991, representando a estratégia adotada para a "retomada do desenvolvimento". ACM declarava então que

O PROBAHIA tem como mecanismo financeiro o Fundo de Promoção do Desenvolvimento Industrial - PROIND, gerido pelo DESENBANCO, que concede financiamento correspondente a uma parcela do ICMS, a ser gerado pelas empresas em implantação, recuperação e/ou ampliação, até o limite de 50\%, quando localizadas na RMS, até $75 \%$ no resto do Estado, com prazo de 6 anos para amortização. Em menos de 2 meses, registramos 22 solicitações dos benefícios do PROBAHIA para projetos que somam um investimento superior a US $\$ 200$ milhões (...). O meu Governo abdica do recebimento imediato dos tributos, para estimular o crescimento econômico, beneficiando diretamente as futuras administrações e possibilitando a geração de empregos. Assim age um Governo que pensa primeiramente nos interesses da Bahia e de seu progresso[14].

Na solenidade de lançamento do Programa[15], Paulo Souto, Secretário da Indústria e Comércio durante o Governo ACM, argumentava que os incentivos fiscais contribuiriam para reduzir as necessidades de capital de giro das empresas beneficiárias em seus primeiros anos de operação, criando condições mais favoráveis de amortização dos investimentos realizados em outras fontes[16]. Aquele foi o primeiro passo mais sistemático do Estado da Bahia no cenário da "guerra fiscal".

As empresas que dispõem dos incentivos fiscais recolhem o valor do imposto do consumidor, mas, não o repassam para o Estado. Quando repassam, o faz muito tempo depois em valores desvalorizados. Manifesta-se naquela particularidade um fenômeno mais geral de recrudescimento do egoísmo possessivo na esfera pública em relação a uma receita gerada coletivamente. Essa é uma característica presente no próprio modo de 
ser do Capital na relação com o Trabalho e seus produtos. Temos também um dreno da mais-valia produzida em nível regional por parte do capital que se relocaliza. A questão, a saber, é em que medida esse programa não criaria falsos mecanismos de competitividade no longo prazo.

O resultado principal da guerra fiscal vem sendo a reconcentração da economia Nacional em direção ao Centro-Sul do Brasil, é o que atesta um estudo da Secretaria de Assuntos Fiscais do Banco Nacional de Desenvolvimento Econômico e Social - BNDES, feito com base em análise do Produto Interno Bruto - PIB, cujas conclusões foram citadas pela imprensa:

Entre 1970 e 1985, a região Sudeste havia sofrido uma redução de 6,4\% na participação do PIB. A tendência histórica verificada de queda, no entanto, foi interrompida nos últimos 15 anos. A participação do Sudeste no PIB nacional subiu de 59,1\% em 1985 para 59,6\% em 1998. Já o Nordeste caiu de $13,5 \%$ para $12,6 \%$ no mesmo período. O estudo responsabiliza a guerra fiscal pela mudança dessa tendência histórica. (...) O estudo mostra que o Sudeste aumentou sua participação no PIB da indústria geral de 66,3\% para $68,9 \%$, enquanto o Nordeste caiu de $11,2 \%$ para $7,9 \%$ no período de 1985 a 1998. Entre os Estados, a maior perda nesse quesito é da Bahia, que teve sua participação reduzida de 4,2\% para 2,1\%. A participação de São Paulo aumentou de 46,5\% para 50,6\% em treze anos.[17]

De 1989 a 1999, a participação da Bahia no ICMS Nacional caiu de 4,5\% para 4,1\%. Entre 1985 e 1998 a sua participação no PIB total do País decresceu de 5,1\% para 4,1\%[18].

Ao mesmo tempo em que promovia a renúncia fiscal para as empresas que viessem a se instalar na Bahia, o Governo inicia um processo de saneamento das contas públicas "reativando a fiscalização e deflagrando o combate à sonegação, que deverá prosseguir, sempre em escala maior"[19]. Isso porque para dar vulto à sua proposta de estímulo ao desenvolvimento via privatização do fundo público, o Governo precisaria gerar, inclusive à custa da população local, um "caixa" que viabilizasse os financiamentos iniciais destinados à iniciativa privada. Caracterizava-se uma espécie de "acumulação primitiva" via "expropriação" da população local ao nível dos impostos, necessária ao avanço da industrialização no Estado, particularmente fora da Região Metropolitana de Salvador RMS.

Não eram apenas vantagens fiscais e institucionais que a Bahia oferecia ao Capital. Outros aspectos talvez se revelassem até mais importantes para as empresas que, no contexto da mudança qualitativa no industrialismo, reordenavam sua produção, padrões técnicos e organizacionais. Moscozo, ainda presidente da FIEB, exprimia claramente a visão dos industriais, realçando um dos aspectos estruturantes que vem facilitando a metamorfose 
do industrialismo em moldes competitivistas no Estado da Bahia:

Oferecer recursos novos e isenção de impostos, tudo isso é muito importante. Agora, a Bahia tem condições de atrair novas indústrias, sabe por que? Porque aqui não há muitos problemas como greves, que são pacíficas. E o industrial tem medo de greve. Em estados como Espírito Santo, Pernambuco e São Paulo, é uma desgraça! Agora, em segundo lugar, o governo tem que conseguir recursos mais baratos para a indústria, através do Desembanco [banco de fomento do Estado], e simplificar o processo. É isso que atrai a indústria.[20][grifos nosso]

A burguesia industrial encontrava um campo propício à sua reorganização. O Estado da Bahia "oferece" uma aparelhagem estatal em constante redefinição, segundo a ótica da competitividade subordinada[21], além de novos segmentos operários que, comparados aos trabalhadores do Sul e Sudeste, se encontram menos articulados do ponto de vista classista. Conta ainda com o poder público atuando como eficiente educador estabelecendo, sob a ótica fetichizada da modernidade (em realidade uma "modernização" pós-moderna[22]), uma nova sociabilidade da população para com a aparelhagem estatal e com os setores produtivos.

O PROBAHIA seria um "instrumento de política complementar" para

Dotar a Bahia de mais um fator de atração locacional de grande competitividade, sobretudo para a transformação industrial de matérias-primas e bens intermediários produzidos no Estado.[23]

Acompanhava esse fenômeno uma importante mudança institucional. O Governo reorientava

A máquina administrativa, modernizando a estrutura da área social, dando feição gerencial à área, racionalizando a de infra-estrutura, e fortalecendo a institucional[24] [SIC] [grifo nosso]

A racionalização proposta para a reforma das instituições assumia claramente a lógica gerencial empresarial-privatista[25].

Ao passo em que as reformas tomavam curso, o empresariado baiano se antecipava ao governo estadual e aglutinava forças em torno da nova proposta do Capital para fazer avançá-la. Já em 1993, discutia sistematicamente a reforma do Estado no Encontro sobre Ação do Estado e Competitividade Industrial. Um ponto revelou-se unânime no encontro: a "urgente reorganização do Estado, com redução de gastos e a concentração de investimentos em programas sociais e de infraestrutura"[26]. Cabe questionar de que maneira se poderia investir, ao mesmo tempo, em infra-estruturas e programas sociais diante da declarada crise fiscal do Estado. Seria necessário definir a forma de realização desses investimentos, como também estabelecer prioridades, o que já estava definido por parte da burguesia industrial. 
Reivindicava-se no encontro a desoneração dos custos produtivos, o chamado Custo Bahia (equivalente local do Custo Brasil[27]), além do aumento do investimento estatal em infra-estruturas. Por um lado, a FIEB defendia que o Governo deveria privatizar os setores mais ligados à infra-estrutura (energia, saneamento básico e.t.c). Por outro lado, exigia também que o Estado usasse o fundo público para "modernizar" aqueles setores, tornando-os lucrativos para a exploração capitalista.

A FIEB afirmava que, a exemplo de outros países, o Estado Brasileiro não tem conseguindo promover a modernização ou mesmo a manutenção das infra-esturutras. Defendia então a redefinição das responsabilidades do setor público. Dois aspectos eram destacados como essenciais à viabilização dessa meta[28]:

O primeiro é a forma pela qual o Estado se retira do provimento dessa infra-estrutura criando as novas condições para a área privada no que se trata da "indispensável remuneração dos investimentos e a necessidade precípua de servir o seu destinatário, que é a sociedade". [grifo nosso]

"O segundo é a exigência da percepção desse momento de conversão pelos organismos multilaterais de crédito, aportando sua presença nos financiamentos dessa conversão, não só da infra-estrutura, mas nos programas de privatização, quase sempre exigentes de correlata reestruturação industrial."

Isso porque nenhum empresário iria investir em atividades onde não houvesse previsão de valorização do capital, caso contrário essa atividade deixaria de ser empresarial. Decorre daí a tese defendida pela burguesia de que o Estado deve investir para tornar essas atividades lucrativas. Observamos que esse processo não se daria apenas em setores como energia, estradas, portos e saneamento básico, era também uma tendência para outros serviços sociais, como os da área de saúde.

Nos anos 90, o Governo se aproxima mais organicamente da FIEB, elaborando mais sistematicamente políticas em conjunto. Seguia as proposições defendidas pela CNI, tendendo a tornar a administração pública mais apropriada à exploração privada, ao vincular, por exemplo, a gestão dos serviços estatais à ótica mercantil. O discurso da qualidade é o mote vinculado para tornar senso comum a sociabilidade empresarial na aparelhagem estatal. A visão era de que finalizada a etapa de substituição das importações, o Estado perderia a função de condutor do desenvolvimento social, passando a agir mais como indutor e agência regulatória do que como agente de fomento, e nisso na grande maioria das áreas cobertas pela ação estatal. Seria algo como o Estado vender partes de sua estrutura, agindo como indutor e regulador na área dos serviços sociais, ao passo que disponibilizaria os recursos advindos desse movimento, bem como a própria estrutura desses serviços para o mercado.

Essa tendência, defendida pelo empresariado como necessária à elevação da competitividade social, já era prevista no início da administração ACM, em 1991. Naquele 
momento o Governo baiano tentava mostrar-se como

Um instrumento para a implementação das ações governamentais; na área social, voltadas para o atendimento às carências de nossa (...) população; na área econômica, apoiando o desenvolvimento, principalmente através da implantação de infraestrutura, energia, transportes e saneamento [29][Grifo nosso].

Enfraquecido o seu papel, as políticas sociais são reconvertidas em atendimento às carências. É impossível não lembrar aqui das políticas vitorianas de combate à pobreza na Inglaterra do século XIX, quando esta ação se dava, quando muito, apenas ao nível das carências sociais[30].

\section{A Aparelhagem Estatal Sendo Transformada em sua Forma e Conteúdo}

A seqüência nos caminhos definidos no inicio dos anos 90 era fundamental para os projetos do moderno príncipe industrial (Sistema CNI, do qual faz parte a FIEB), investido no papel de metamorfosear a institucionalidade do Estado na Bahia à sua imagem e semelhança. A continuidade no poder do grupo comandado por ACM contemplaria esse objetivo. Nesse sentido, Paulo Souto, governador eleito nas eleições de 1994 (em 1998 seria eleito senador) daria prosseguimento à filosofia de governo inaugurada em 1991, afinando seu discurso com o projeto mais amplo do Sistema CNI, cujo representante local é a FIEB. Para a burguesia industrial ficava "a certeza de que o relacionamento governoempresariado tem tudo para se estreitar", como realmente se estreitou[31]. Assim, se na primeira metade dos anos 90 foram lançadas as bases para reformas, a partir de 1995 as mudanças começam a alterar de forma mais substantiva a face da aparelhagem estatal baiana. Não é por acaso, inclusive, que a partir daquele momento, o Estado da Bahia torna-se um importante pólo de atração de novos investimentos industriais provenientes do Centro-Sul.

Em debate realizado em novembro de 1994, o novo governador apresentava para os industriais as metas do seu governo, apontando o eixo da sua política de desenvolvimento sócio-econômico:

Farei, a partir de idéias práticas e realistas, tudo para que não tenhamos em relação aos outros estados nada que prejudique a nossa industria. Estou disposto a encarar propostas que nos deixem, pelo menos, em condições de competitividade igual em relação a outros estados, mesmo que implique em eventual perda de receitas. [32] [grifo nosso]

A tendência é do Estado perder não somente capacidade de gerar receita, mas também de reduzir em longo prazo sua capacidade de investir tanto na área social quanto em setores 
diretamente ligados à reprodução ampliada do Capital.

A partir do Governo Paulo Souto e, posteriormente, durante o Governo César Borges, a racionalização administrativa seria acompanhada por privatizações de empresas e serviços públicos estatais. Há, inclusive, mudanças quanto às concepções sobre a função dos investimentos nas áreas sociais. Os investimentos passam também a ser feitos apontando para os serviços sociais estatais a possibilidade de se tornarem "autônomos" do poder público, como prevê o sistema de Organizações Sociais - OS. Praticando as idéias debatidas com o Capital, como também influenciado pela tendência manifesta no Governo Federal, durante o triênio 1995-1997 o Governo do Estado da Bahia adota formas diferenciadas de encaminhar as políticas sociais. Através das OS descentraliza-se o controle do fundo público através de "modelos alternativos de gestão" [33]. Transferia-se a administração de políticas públicas, sobretudo na área de saúde, para entidades nãogovernamentais. O Programa compõe um conjunto de mudanças no setor público com o fim de:

Encontrar novas formas de parceria com a sociedade, através da descentralização da execução de atividades públicas para instituições qualificadas da sociedade civil, [propiciando] um melhor gerenciamento e autonomia financeira a certos serviços fundamentais a serem administrados por organizações sociais sem fins lucrativos, tais como saúde, educação, pesquisa científica e tecnológica, cultura e meio ambiente. E, ao contrário do que se disse, isto se fará sob supervisão do Estado, que exercerá sobre elas o indispensável controle para garantir a qualidade e equidade na prestação dos serviços [34].

Se por um lado declara-se que as OS não teriam fins lucrativos, por outro lado elas possuem natureza jurídica de direito privado. Pode-se questionar até quando as organizações sociais não teriam fins lucrativos. As fontes apontam os caminhos da resposta:

Na condição de entidade de direito privado as OS podem administrar os seus recursos com autonomia, adotando referenciais de qualidade e produtividade praticados pelo mercado.[35]

Observa-se aqui a nova proposta do Capital se concretizando. As ações citadas tendem a se constituir em estratégias de transição cujo fim é viabilizar a exploração mercantil de serviços sociais para, em seguida, disponibiliza-las para o mercado. Os recursos das OS, estes se originariam de

Subvenções sociais pelo exercício de suas atividades; doações e contribuições de entidades nacionais e estrangeiras; rendimentos de aplicações e de seus ativos financeiros 
e outros pertinentes ao patrimônio; serviços sob a sua administração na forma do contrato de gestão; outros recursos que lhe venham a ser destinados.[36]

Quanto ao papel do Estado as fontes também não deixam muitas dúvidas:

Ficará à cargo da Secretaria da Administração do Estado o acompanhamento estratégico e a avaliação do desempenho global do Programa Estadual de Incentivo às organizações Sociais. (...). É no controle sobre os resultados, na capacidade de avaliação e na constante identificação das demandas da sociedade que residem as garantias da efetividade desta nova forma de prestação dos serviços.[37]

O Governo fala em garantia de recursos para as OS, destacando que as mesmas não teriam fins lucrativos. Mas, ao mesmo tempo, diz que essas organizações poderão dispor dos recursos segundo a lógica de produtividade do mercado. "Confunde" então no seu discurso duas lógicas distintas: a pública e a do mercado. Na lógica do mercado a produtividade não necessariamente anda lado a lado com o senso de coletividade, que tenderia a constar na perspectiva da esfera pública. Para o mercado produtividade é sinônimo de otimização do capital e nesse processo não se leva em conta interesses sociais coletivos: se for lucrativo privilegiar certos serviços e segmentos da sociedade agora mais do que nunca "segmento do mercado" - em detrimento de outros, para o mercado não há problema em assim fazê-lo, o importante é a produtividade, a lucratividade e otimização das estruturas e recursos. Fica difícil imaginar como o Governo regularia e enfraqueceria essa lógica, visando a coletitividade, se o mercado tende a afirmá-la. O modelo proposto pelo Governo estadual revela-se cada vez menos capaz de resolver essa contradição.

A política adotada tenta estabelecer a aceitação consensual e a sociabilização do pressuposto de que a interação democrática do indivíduo com a sociedade ocorra, privilegiadamente, através do mercado[38]. O Governo atua claramente como educador: interage reconstruindo pedagogicamente uma nova hegemonia, procurando estabelecer um novo senso comum sobre o papel da aparelhagem estatal perante o Estado em sentido ampliado. O setor público tende agora a exercer uma função semelhante à das agências reguladoras, cujo princípio é o de zelar pela qualidade dos "serviços públicos não-estatais" sem garanti-los. O argumento é de que há "necessidade de se redefinir o papel e o tamanho do Estado na economia" por conta da "crise fiscal, caracterizada pela redução da capacidade de investimentos do Estado"[39]. Mas, contraditoriamente, o Governo promoverá a renúncia fiscal em relação à taxação do Capital, ampliando também sua capacidade de investimentos para financiar a acumulação privada. Após 1995, quando as reformas do Estado e privatizações ganham ênfase, a capacidade de investimento estatal se eleva e a estratégia supracitada começa dar resultados:

Mantendo as suas despesas de pessoal e custeio dentro de padrões compatíveis com a 
política de equilíbrio das contas públicas, a Bahia ampliou a sua capacidade de investimentos, que em 1997 chegou a $R \$ 953$ milhões, sendo $R \$ 525$ milhões de recursos próprios e $R \$ 428$ milhões provenientes de financiamentos, transferências federais e convênios. Na realidade no último triênio [1995-1997] o investimento público direto cresceu 124\%, ou seja de R\$ 425 milhões, em 1995, saltou para 953 milhões em 1997 [40] [grifo nosso]

Os dados encarnam uma aparente contradição, já apontada como tendência. O Estado tende a "encolher" sua aparelhagem de satisfação das demandas sociais ao mesmo tempo em que "expande" sua capacidade financeira. A contradição é aparente porque diante da declarada escassez dos recursos, a existência do "Estado máximo" para uns pressupõe a existência do "Estado mínimo" para outros: máximo e fomentador para a acumulação privada, e mínimo e regulador para as demandas sociais via privatização do fundo público.

Em 1998 o Governo do Estado registrava que a Bahia vivenciava

um permanente processo de reforma e modernização das estruturas, práticas e procedimentos que estão transformando a administração burocrática em administração participativa e gerencial e otimizando o desempenho do setor público.[41]

O discurso contrapunha o termo "burocracia" à "eficiência". Administração burocrática corresponderia ao Estado "pesado" e administração gerencial corresponderia ao Estado mais ágil flexível. Melhorar a administração pública é uma necessidade histórica no Brasil. Ocorre que a ótica de racionalização ali presente se aproxima de uma perspectiva de despolitização e despublicização do Estado, como se mudanças técnico-organizacionais por si resolvessem os problemas, minimizando algo anterior ao processo: as implicações e os objetivos finais do projeto de racionalização. Um exemplo disso é o Serviço de Atendimento ao Cidadão - SAC. Criado em 1995, quando se aprofunda o chamado processo de modernização do setor público na Bahia, o SAC constitui uma iniciativa pioneira no Brasil. A sua função é agilizar sensivelmente a expedição de alguns documentos essenciais (cédulas de identidade, antecedentes criminais, serviços fiscais, dentre outros) configurando-se como uma espécie de loja de serviços, sendo elogiado até mesmo no exterior. Em vista da proposta mais global de reforma do Estado, percebe-se na atuação do SAC a tendência anteriormente apontada de mercantilização/viabilização econômica da prestação dos serviços públicos na medida em que são cobrados. Ou seja, são agilizados os encaminhamentos burocráticos em ambientes relativamente confortáveis, elevando-se o grau de eficiência desses serviços ao passo que se estabelecer um custo que torne essa atividade viável do ponto de vista mercantil. Mesmo que os preços cobrados pelos serviços do SAC venham a ser mais elevados do que os que eram pagos, ou mesmo não eram pagos antes da sua criação, do ponto de vista do conforto eles são compensados quando se considera a comodidade e agilidade na nova forma de prestação desses serviços. Caberia uma reapropriação da idéia do SAC, desta vez em uma perspectiva de sociedade efetivamente publicizante e democrática. $O$ fundamental não é puramente a comodidade e a eficiência do serviço prestado à população, mas também as estratégias adotadas para viabilizar essa realidade, pois 
implica em quais setores serão ou não atendidos.

A tendência mais geral de elevação da qualidade dos serviços estatais relacionada à sua transformação em um filão comercialmente atrativo, aproximando-se da estratégia de investir para privatizar, é claramente explicitada por Bresser Pereira, importante intelectual orgânico desse projeto burguês:

A administração pública gerencial vê o cidadão como cliente, como o destinatário dos seus serviços.(...). À avaliação sistemática, à recompensa pelo desempenho, e à capacitação permanente, que já eram características da boa administração burocrática, que acrescentam-se [sic] os princípios da competição administrada, do controle por resultados, e da orientação para o cidadão-cliente.[42]

Sob discurso da qualidade se realiza uma importante tentativa de resignificação conceitual: não se fala mais em cidadão, mas em cidadão-cliente. No cenário baiano, operando essa tentativa no campo simbólico, o Governo procura educar as pessoas para que estas se vejam na relação com a aparelhagem estatal como clientes frente a uma espécie de prestadora de serviços, cujo produto final a ser adquirido fosse o serviço social tendencialmente convertido em produto-mercadoria. Redefinidas conceitualmente como cidadãos-clientes, as pessoas teriam então que rever suas concepções sobre o papel da aparelhagem estatal. A idéia do que seja esfera pública é então modificada. Fala-se agora em "publicizar" a gestão e serviços estatais transferindo-os totalmente ou parcialmente para a sociedade civil. Ocorre que na perspectiva neoliberal, o núcleo sadio da sociedade civil é a sua versatilidade, flexibilidade e racionalidade próprias do modo de ser do Capital, elemento fundamental de sociabilização na ótica empresarial, onde todos deveriam se apresentar como vendedores/produtores e consumidores. Daí a proposta de um Estado estrito senso que tende a se converter em uma espécie de agência supervisora dos serviços públicos não estatais. Por conta do viés neoliberal que informa essa proposta, o que tende a ocorrer não é exatamente uma publicização desses serviços, no sentido de sua substantiva democratização. Isso porque na perspectiva do mercado, os cidadãos não são iguais (na verdade o mercado não usa o termo cidadãos e sim consumidores, clientes): sua diferença, hierarquização e formas de tratamento são determinadas pelo seu poder de consumo. Desse modo, a reforma encaminhada enfraquece a idéia de "coisa pública", naquele sentido clássico de estar associada a um Estado que equilibraria mais eficientemente as diferenças sociais (ao menos era o que se tentava fazer crer). Ao mesmo tempo, associa-se à aparelhagem estatal a imagem de eficiência administrativa nos marcos da lógica de mercado, que historicamente tende a cristalizar diferenças na hierarquia social.

Se os clientes não são todos iguais, sendo seu acesso aos serviços não-públicos determinados pelo seu poder de compra, por acaso seriam todos iguais os cidadãos [- 
clientes] frente a uma aparelhagem estatal "publicizada" (na verdade despublicizada) que presta serviços públicos não-estatais próximos da ótica mercantil? Quem teria a primazia nessa relação, o "cidadão" ou o "cliente"? A primazia tende a ser do cliente convertido em consumidor de mercadorias, a menos que se altere a atual correlação de forças. Aponta-se então para a mercantilização da cidadania. O Estado e seus serviços se tornam cada vez mais à imagem e semelhança do próprio Capital[43]. Portanto, as palavras e conceitos não são neutros.

Sobre as privatizações o Governo baiano afirmava que estas seriam realizadas em "atividades para as quais já não existem razões de interesse social que justifiquem a sua execução pelo poder público"[44][grifo nosso]. Essa tendência se manifestaria inicialmente na área de saúde com a adoção das OS. Pode-se perguntar se não há, na gestão da área de saúde, razões de interesse social por parte do Estado, ou se essas razões diminuíram. Outro argumento era de que as privatizações estavam sendo feitas em áreas cujo Estado precisaria dispor de grande quantidade de recursos para garantir sua competitividade, e que os recursos captados em tais operações apresentar-se-iam como incrementos a serem investidos na área social, representando não apenas uma tendência, mas também um imperativo da nova ordem econômica[45]. Há aqui uma contradição: se a previsão era de "enxugamento" da máquina estatal, cuja função seria mais reguladora do que de fomento, prevendo-se inclusive a privatização de serviços sociais, seria importante identificar onde seriam investidos os recursos gerados pela privatização. Certamente, o Estado não voltaria a ampliar suas estruturas reinvestindo ali aqueles recursos, "inchando" novamente. Aquele montante tenderia a compor o processo de privatização do fundo público em curso.

A linearidade estabelecida entre privatização e elevação da eficiência é uma ótica particular (próxima da empresarial) de leitura do real. A eficiência no setor público não é necessariamente correlata à privatização de setores fundamentais ao bem-estar coletivo. Mesmo intelectuais próximos da burguesia admitem isso. Em entrevista ao Sistema FIEB, Celso Bandeira de Mello defendia as privatizações, mas admitia que deveriam ser feitas com critério: "Acho que o Estado brasileiro na presente quadra histórica é mal administrador". Contudo, mesmo fazendo ressalvas à historicidade brasileira, Mello acaba vendo o problema administrativo como uma característica imutável, aparentemente apreende a realidade numa perspectiva a-histórica, não pressupõe que o Estado vá melhorar a sua eficácia, recomenda então a privatização:

Não sei se a estatização ou privatização em abstrato é boa ou má. Não creio que possa dar resposta a isso. Só é possível avaliá-la de acordo com o tempo e local. Na realidade brasileira o que estiver em mãos do Estado é apenas um instrumento de ineficiência, de corrupção ou de profundo desprezo pelas camadas sociais mais desamparadas. Não tenho no estado a menor esperança no Estado [sic]. Ele é uma coisa abstrata, é um reflexo dos homens que o dirigem. O Estado brasileiro, na verdade, sempre pertenceu a grupos de interesses que têm nele um instrumento. Ora, é melhor mesmo que muito da sua atual 
estrutura vá direto para esses particulares[46] [grifo nosso]

Para João Quadros, coordenador dos estudos encomendados pela FIEB sobre "Custo Bahia" (1996),

Criou-se uma falsa idéia de que o Estado da Bahia é um mal administrador. É que infelizmente nós tivemos no Brasil uma má administração de empresas que estão na mão do Estado. Mas aqui mesmo na Bahia temos exemplo de empresas que, administrada pelo Estado, se mostraram competentes e com respostas às exigências do mercado. Não é o

Estado que é o causador do mal. Mas a questão é gerencial. Existem no setor público empresas bem e mal administradas, como existem no setor privado. [47] [grifo nosso]

O debate não se resume às empresas estatais. A questão gerencial está aqui associada à mudança cultural na aparelhagem estatal, inclusive no sentido de dotar seus gestores de visão empreendedora na ótica do Capital, redefinindo os serviços estatais na direção de otimização de recursos na lógica empresarial. Como agora caberia ao Estado o papel de "regulador", essa mudança cultural prepara a aparelhagem estatal para as regras do mercado. Por trás disso há uma visão mais global de modificação da sociabilidade, onde todos deveriam incorporar a cultura empreendedora empresarial para conviverem de forma competitiva em uma sociedade subsumida mais profundamente aos valores ético-políticos do mercado (Sociedade Competitiva), próximo do que Friedman já defendia[48], ao argumentar que só o mercado gera democracia, liberdade, eficiência.

Na conjuntura 1995-1997 o Governo do Estado mostrava-se ciente das intensas transformações que se faziam sentir em todos os setores da vida humana, destacando como pano de fundo dessa realidade o papel da "globalização" econômica, assumindo a competência e a competitividade como questões vitais para a inserção da Bahia nessa etapa do capitalismo, uma visão que já constava no seio da FIEB desde os anos 80 . Na segunda metade da década de 90 o Governo baiano começa a definir uma estratégia mais sistêmica para o desenvolvimento industrial do Estado. Mas, não encontraremos a explicação para essa mudança apenas no Estado estrito senso. Podemos localizar essas transformações ocorrendo na FIEB, ao menos enquanto tendência de conteúdos econômicos e ético-políticos mais amplos defendidos pela CNI. O Governo baiano adotava tais princípios se antecipando, muitas vezes, à própria reforma do Estado em nível federal.

Assim, em janeiro de 1995 a FIEB publicava um estudo que causariam eco na aparelhagem estatal baiana: Industrialização na Bahia - Construindo uma Nova Estratégia [49]. A nova proposta para o desenvolvimento industrial do Estado tomava como base o processo de ruptura "do modelo autárquico de desenvolvimento industrial no país". Na solenidade de lançamento do documento, José de Freitas Mascarenhas, então presidente da FIEB, declarava que há algum tempo o empresariado baiano estava ansioso com relação ao futuro industrial do Estado. Segundo Mascarenhas[50], a indústria baiana passava, no período, por uma crise de identidade, expressa na desarticulação de sua trajetória passada e na incerteza quanto as suas perspectivas, contidas nas suas 
possibilidades de conferir um ambiente sustentável de crescimento. O desafio para o empresariado e governo baianos era a inserção da economia local no novo "padrão de desenvolvimento nacional", ajustando o seu parque produtivo às condições estruturais e institucionais requisitadas pela nova configuração do capitalismo internacional. A FIEB reafirmava sua visão de que essa ação era condição indispensável para a retomada do crescimento da economia baiana, assim como para elevar o padrão de competitividade estadual via novos investimentos produtivos, bem como para criar condições favoráveis a reinvestimentos no próprio Estado[51]. Segundo o Governo baiano, o estudo representava um verdadeiro marco, em um momento em que a união de esforços em nome do desenvolvimento do Estado era fundamental[52].

Entre 1995-1997, o Governo baiano sintoniza mais organicamente seu discurso com o dos empresários. A burguesia industrial desequilibra ainda mais a correlação de forças em seu favor. Tende a reificar e subordinar de forma mais eficiente à sua perspectiva de classe os anseios da população usando o mote da modernização. Reafirma-se a nova proposta do Capital, que não se restringe a aspectos pontuais de política econômica, mas supõe sua articulação com um projeto mais global de sociedade. Isso resultou, em 1998, na presença da FIEB, a convite do Governo estadual, formulando a política estratégica do Estado para o desenvolvimento do setor industrial sem mediação com outros setores organizados da sociedade civil, como demonstram as afirmações do presidente da entidade patronal na apresentação do "Programa Estratégico de Desenvolvimento Industrial do Estado da Bahia":

Em dezembro de 1995 a FIEB apresentou o estudo "Industrialização na Bahia Construindo uma Nova estratégia”, [estudo já citado] onde resumia suas percepções sobre como deveria ser tratada a questão do desenvolvimento industrial do nosso Estado, tendo em vista o novo contexto de globalização das economias. Entendimentos subseqüentes com o Governador Paulo Ganem Souto e seus secretários do Planejamento, Ciência e Tecnologia, e da Indústria, Comércio e Mineração, conduziram a que o Estado confiasse à FIEB, através de convênio, a elaboração deste Programa Estratégico de Desenvolvimento Industrial do Estado da Bahia[53].

Revela-se o poder da fração baiana do "moderno príncipe industrial", demonstrado também empiricamente na Bahia certo nível de materialização das suas estratégias e concepções mais globais de interação com o Estado - cada vez mais unilaterais -, às quais Rodrigues já se referia[54]. O programa foi formulado após uma

Consulta ampla às lideranças econômicas e políticas do Estado, além de empreendedores com interesses na Bahia. Todo o esforço, coordenado pela FIEB, visou levantar as principais bases para a nova proposição com vista ao desenvolvimento industrial do Estado.[55] 
No Estado da Bahia, os empresários já formulam diretamente políticas públicas, reforçando tendências despublicizantes na aparelhagem estatal, de apropriação privada dos recursos públicos, como também materializando uma sociabilidade privatista via penetração do ethos empresarial no Estado estrito senso. A nova estratégia não se reduz nesse nível, diz respeito à própria formação intelectual e ético-política das futuras gerações, pretendendo uma mudança mais totalizante. O projeto é explicitado em entrevista concedida pelo empresário Noberto Odebretch a um periódico da FIEB, sintetizando os anseios da burguesia em metamorfosear a sociabilidade no cenário da crise do trabalho assalariado, afirmando ainda aspectos do que seria a "Sociedade do Conhecimento": Segundo Odebretch

$\mathrm{Na}$ era em que vivemos, a pessoa de conhecimento deve comportar-se como empresária de seu saber, de sua competência e de suas habilidades. Em vez de ambicionar salário, deve ambicionar a justa partilha dos resultados que contribui para gerar. É por esta razão que devemos preocupar-nos muito em oferecer, sobretudo aos adolescentes, uma nova educação; uma educação empresarial que os habilite a enriquecer moral e materialmente num mundo no qual teremos cada vez menos assalariados. Nossos jovens precisam aprender que, em vez de patrões, precisam é identificar, conquistar e satisfazer clientes.[56] [sem grifo no original]

No capitalismo a "justa partilha de resultados" é uma quimera[57]. A distribuição dos resultados é ontologicamente desigual em relação aos esforços dos sujeitos (capitalistas e trabalhadores) envolvidos no processo de produção, caso contrário o metabolismo do Capital não se sustentaria. Mas, fundamental aqui é que essa última citação mostra o grau de organicidade e clareza do Capital no objetivo de metamorfosear o bloco histórico, ao tentar constitui-lo de forma mais total e profunda à sua imagem e semelhança, vinculado para a sociedade valores ético-políticos que pertencem à sua perspectiva de classe.

\section{Conclusão}

Ao longo dos anos 90 uma interlocução mais afinada com a fração local do "moderno príncipe industrial" vem contribuindo para que o Governo do Estado da Bahia modifique a institucionalidade estatal e sua política para o desenvolvimento sócio-econômico em direção às demandas atuais do Capital, que passa também pela privatização do fundo público e pelo avanço do ethos empresarial no cotidiano. O conteúdo dessas mudanças compõe transformações no bloco histórico correspondente à hegemonia produtiva do 
industrialismo americanista, atualmente em crise, denunciando mais uma modernização conservadora. Na singularidade baiana temos então um dos momentos de um movimento mais total, cujo resultado propõe o estabelecimento da Sociedade Competitiva. O lema vinculado na mídia nacional pelo Governo estadual é: "Bahia: 10 anos no caminho certo". Caminho certo para quem? Caso não se mude a correlação de forças, os resultados desse caminho tendem a beneficiar cada vez menos o conjunto da população baiana. Traçamos aqui algumas tendências sobre as atuais transformações do Estado e do modelo de desenvolvimento na Bahia. Isso não quer dizer que não haja fissuras nesse processo ou que, em outra perspectiva de télos societal que não na ótica do Capital, as mudanças não possam vir a ter um conteúdo vinculado a uma proposta de real desenvolvimento social para todos.

\section{Referências Bibliográficas:}

BAHIA. Governo do Estado da Bahia. Organizações Sociais. Salvador-Ba, consultado em 08/11/2000. (www.bahia.ba.gov.br/saeb/oRSociais)

BAHIA. Governo do Estado da Bahia. Relatório de Atividades. (relatórios de 1984 a 2001).

BAHIA. Secretaria do Planejamento, Ciência e Tecnologia. Superintendência de Planejamento Estratégico. A Indústria Calçadista na Bahia. Salvador, Superintendência de Planejamento Estratégico, 2000.

$\mathrm{CNI}$ - Confederação Nacional da Indústria. Custo Brasil: agenda no Congresso Nacional. Rio de Janeiro: CNI, 1996.

CRUZ, Sebastião C. Velasco. Estado e Economia em Tempos de Crise: política industrial e transição política no Brasil nos anos 90. Rio de Janeiro-RJ: Relume Dumará; Campinas-SP: Editora da Universidade de Campinas, 1997.

Federação das Indústrias do Estado da Bahia - FIEB. BAHIAINDÚSTRIA. Salvador-Ba, ano I, n 12 ao no 40 .

Federação das Indústrias do Estado da Bahia - FIEB. Boletim Industrial. Salvador-Ba, $\mathrm{n}^{\circ}$ 377 ao $\mathrm{n}^{\circ} 414$ e Ano I, ํo 3 ao 7

Federação das Indústrias do Estado da Bahia - FIEB. Departamento de Economia. Industrialização na Bahia: construindo uma nova estratégia. Salvador-Ba, 1995.

Federação das Indústrias do Estado da Bahia - FIEB. Orlando Moscozo.

Pronunciamentos e Posições Assumidas: 1983-1986. Salvador-Ba, 1986.

Federação das Indústrias do Estado da Bahia - FIEB. Programa Estratégico de Desenvolvimento Industrial do Estado da Bahia. Salvador-Ba: FIEB/SEI [SEI - 
Superintendência de Estudos Econômicos e Sociais da Bahia, órgão estadual vinculado à Secretaria de Ciência e Tecnologia - SEPLANTEC], 1998.

FERRAZ, Cristiano L. Metamorfose do Industrialismo no Estado da Bahia: Estado, Produção e Formação Humana. Dissertação de Mestrado. Programa de Pós-graduação em Educação - mestrado e doutorado - da Universidade Federal Fluminense, campo de confluência Trabalho e Educação. Niterói-RJ, 2002.

Folha de São Paulo, ano 80, № 25.890: São Paulo, 20 de fevereiro de 2000.

FRIEDMAN, Milton. Capitalismo e Liberdade. 3를. Eão Paulo-SP: Nova Cultural, 1988.

GRAMSCI, Antônio. Maquiavel, a Política e o Estado Moderno. $6^{\text {A }}$ Edição. Rio de Janeiro-RJ: Civilização Brasileira, 1988.

HARVEY, David. Condição Pós-Moderna. São Paulo-SP: Edições Loyola, 1992.

HELLER, Agnes [et alli ]. A Crise dos Paradigmas em Ciências sociais e os Demais desafios para o Século XXI. Rio de Janeiro-RJ: Contraponto, 1999.

JAMENSON, Fredric. Pós-modernismo: a lógica cultural do capitalismo tardio. São Paulo-SP: Editora Ática.

LOPES, Juarez R. B. Crise no Brasil Arcaico. São Paulo-SP: Difusão Européia do Livro, 1967.

MARTINS, Luciano. Estado Capitalista e Burocracia no Brasil pós-64. Rio de JaneiroRJ: Paz e Terra, 1985.

MARX, Karl \& ENGELS, Friedrich. Obras Escolhidas. São Paulo-SP: Alfa-Ômega, 1986.

McCLELAND, David C. A Sociedade Competitiva: realização e progresso social. Rio de Janeiro-RJ: Expressão e Cultura, 1972.

OLIVEIRA, Francisco de. Os Direitos do antivalor: a economia política da hegemonia imperfeita. Petrópolis-RJ: Vozes, 1998.

PEREIRA, Luiz Carlos Bresser. Plano Diretor da Reforma do Aparelho Estatal.

Administração Pública. Brasília-DF: Editora Brasil LTDA, 1996

RODRIGUES, José. O Moderno Príncipe Industrial: o pensamento pedagógico da Confederação Nacional da Indústria. Campinas-SP: Autores Associados, 1998.

RODRIGUES, Leôncio, M. Industrialização e Atitudes Operárias: estudo de um grupo de trabalhadores. São Paulo-SP: Editora Brasiliense, 1970.

[1] Doutorando em Ciências Sociais pela Unicamp, na área Trabalho, Política e Sociedade.

[2] Cf: RODRIGUES, José. O Moderno Príncipe Industrial: o pensamento pedagógico da Confederação Nacional da Indústria. Campinas-SP: Autores Associados, 1998. 
[3] Rodrigues denomina de Télos da Economia Competitiva o novo estágio social proposto pela Confederação Nacional da Indústria - CNI para o Brasil. Segundo Rodrigues, em vários momentos da história da industrialização brasileira, a partir das primeiras décadas do Século XX, encontramos a CNI se articulando em torno de projetos globais de sociedade. Assim temos nas primeiras décadas do século aqueles empresários defendendo a industrialização no Brasil: o Télos Industrialista. Consolidada a industrialização, a CNI se depara com a necessidade de elevar a competitividade industrial do país frente à "globalização" da economia. Propõe agora o que Rodrigues chama de Télos da Economia Competitiva, que seria a proposta da confederação de fazer penetrar o ethos empresarial na aparelhagem estatal, na formação humana, no universo dos trabalhadores e mesmo na sociabilidade: todos deveriam se comportar como empresários. Ao nosso ver a consecução desses objetivos resultaria em uma "Sociedade Competitiva". MacClelland também emprega o termo "sociedade competitiva", mas de maneira diferente da que usamos. No início dos anos 60, MacClelland publica nos EUA sua obra "A Sociedade Competitiva: realização e progresso social". Nessa obra o autor procura "isolar" e "medir" fatores psicológicos que possam explicar os motivos que levaram algumas sociedades a se desenvolverem mais do que outras. Para isso o autor se vale de estudos sobre o comportamento humano em diversas sociedades buscando "medir" o grau de iniciativa e realização (para o autor esses dois fatores implicam em "atitude empresarial") em sociedades tão dispares quanto grupos cujo modo de vida nos remete ao neolítico e sociedades capitalistas. Ao nosso ver o autor incorre, então, em sério anacronismo ao transplantar valores burgueses para sociedades não-capitalistas. Usamos o termo "Sociedade Competitiva" em uma acepção diferente da trabalhada por MacClelland. Enquanto para aquele autor os atributos da sociedade competitiva estariam na base da explicação "do desenvolvimento e da decadência das nações", para nós a Sociedade Competitiva - um desdobramento do modelo teórico telos da Economia Competitiva, desenvolvido por Rodrigues - constitui um projeto social que a burguesia procura concretizar, quando os valores ético-políticos empresariais permeariam toda a sociedade, mesmo o cotidiano, desde as relações de trabalho e políticas até as relações pessoais, quando o Capital passaria a colonizar mais profundamente diversos espaços da vida social, tentando subsumir ainda mais as coisas à sua lógica, para além das relações de produção e da aparelhagem estatal, que também deveriam se adequar a essas proposições. Enquanto para MacClelland a Sociedade Competitiva é a causa do desenvolvimento, para nós ela é um projeto que a burguesia procura construir para a resolução da atual crise orgânica do capitalismo. Ver: McCLELAND, David C. $\boldsymbol{A}$

Sociedade Competitiva: realização e progresso social. Rio de Janeiro-RJ: Expressão e Cultura, 1972. Sobre o conceito de Télos da Economia Competitiva, ver: RODRIGUES, José. O Moderno Príncipe Industrial: o pensamento pedagógico da Confederação Nacional da Indústria. Campinas-SP: Autores Associados, 1998, Cap. III.

[4] Sobre as características do bloco histórico americanista ver: Americanismo e Fordismo. In: GRAMSCI, Antônio. Maquiavel, a Política e o Estado Moderno. $6^{\mathrm{A}}$ Edição. Rio de Janeiro-RJ: Civilização Brasileira, 1988.

[5] Para uma abordagem metodológica sobre a relação entre mudanças na organização da produção social da vida com as mudanças nas forças produtivas, na política, enfim, no modo de vida, ver: MARX, Karl. Prefácio à "Contribuição da Economia Política". In: MARX, Karl \& ENGELS, Friedrich. Obras Escolhidas Vol. 1. São Paulo-SP: Alfa-Ômega, 1986, p. 331.

[6] Cf: FERRAZ, Cristiano L. Metamorfose do Industrialismo no Estado da Bahia:

Estado, Produção e Formação Humana. Dissertação de Mestrado. Programa de Pósgraduação em Éducação - Mestrado e Doutorado - da Universidade Federal Fluminense, campo confluência Trabalho e Educação. Niterói-RJ, 2002. 
[7] Observamos essas características ao investigar alguns aspectos sobre o lugar da formação profissional nesse processo mais amplo de mudanças na organização da produção social da vida. Para isso, pesquisamos mudanças que ocorreram nas estratégias de qualificação profissional do SENAI - Departamento Regional do Estado da Bahia a partir de 1984, motivadas por novas necessidades ético-políticas e tecno-científicas na organização do trabalho, que se metamorfoseia junto com o industrialismo americanista. Ver: FERRAZ, Op. Cit., capítulo III.

[8] Cf: BAHIA. Governo do Estado da Bahia. Relatório de Atividades de 1986: Mensagem do Governador à Assembléia Legislativa do Estado da Bahia. SalvadorBa, março de 1987, p. 4.

[9] Federação das Indústrias do Estado da Bahia - FIEB. Orlando Moscozo.

Pronunciamentos e Posições Assumidas: 1983-1986. Salvador-Ba: FIEB, 1986, p. 9.

[10] Essa reivindicação da FIEB se faria presente mesmo nos anos seguintes, quando as tendências desenvolvimetistas já se encontrassem tendencialmente fora da pauta de discussão dos grupos hegemônicos dentro do Governo Federal. Sobre essa tendência no Governo Federal, ver: CRUZ, Sebastião C. Velasco. Estado e Economia em Tempos de Crise: política industrial e transição política no Brasil nos anos 90. Rio de Janeiro-RJ: Relume Dumará; Campinas-SP: Editora da Universidade de Campinas, 1997.

[11] Federação das Indústrias do Estado da Bahia - FIEB. Orlando Moscozo.

Pronunciamentos e Posições Assumidas: 1983-1986. Salvador-Ba: FIEB, 1986, p. 25.

[12] Na segunda metade dos anos 80 o que se percebe é justamente certo nível de atrito entre o comando da FIEB e o Governo Estadual. Naquele momento observa-se, inclusive, ambos trocando farpas pela imprensa. Cf: "Moscozo Alerta para Golpe das

Esquerdas" (Tribuna da Bhaia, página 1 -08/12/88). "A Advertência de Moscozo" (Tribuna da Bahia - Editorial - 12/88). "Waldir Quer Conservadores Indo às Ruas: governador estranha discurso de empresários e afirma que esquerdas não representam ameaça". (tribuna da Bahia - Página 3 - 09/12/88). In: Federação das Indústrias do Estado da Bahia - FIEB. Orlando Moscozo. Política: Pensamento e Ação. Salvador-Ba: FIEB, (?).

[13] Federação das Indústrias do Estado da Bahia - FIEB. A Bahia Deve Repensar seu Modelo Industrial. Boletim Industrial. Salvador-Ba, v. 22, $n^{\circ} 377$, jan. 1988, p. 7.

[14] BAHIA. Governo do Estado da Bahia. Relatório de Atividades de 1991 - Mensagem do Governador. Salvador-Ba, fevereiro de 1992 p. VI.

[15] Governador Lança os Programas para Desenvolver mais a Bahia. In: Federação das Indústrias do Estado da Bahia - FIEB. Boletim Industrial. Salvador-Ba, ano $26, \mathrm{n}^{\circ} 414$, nov. 1991, p. 7.

[16] Os incentivos fiscais fazem parte das políticas públicas de desenvolvimento no Nordeste desde os anos 50, em nível federal, e, de certa forma contribuíram para uma maior descentralização produtiva. Mas, é só a partir da Constituição de 1988 que, buscando acelerar o processo de descentralização fiscal, foi ampliada a autonomia financeira de Estados e municípios para arrecadarem seus tributos e realizarem seus orçamentos. Isso contribuiu para melhorar a receita estadual, proporcionando a prática de benefícios fiscais concedidos pelos Estados. A estagnação econômica dos anos 90 fez com os Estados ampliassem ainda mais o regime de incentivos para atraírem investimentos externos, criaram-se assim vários programas de atração, acirrando a "guerra fiscal", o que se deu mais sistematicamente nos anos 90. Na Bahia o marco é a 
implementação das políticas de estabilização iniciadas com o Governo ACM em 1991. Ver: BAHIA. Secretaria do Planejamento, Ciência e Tecnologia. Superintendência de Planejamento Estratégico. A Indústria Calçadista na Bahia. Salvador, Superintendência de Planejamento Estratégico, 2000, p. 27-28. Os incentivos fiscais seriam utilizados até 1998, quando foram abandonados por serem inconstitucionais. A partir de então o Governo baiano passaria a estudar novas formas de incentivos para atrair empreendimentos industriais. Nas fontes que pesquisamos com data posteriores a 1998 não havia ainda uma proposta formulada.

[17] "Disputa concentra economia, diz BNDES". Seção Brasil, p. 15. Folha de São Paulo, ano 80, № 25.890: São Paulo, 20 de fevereiro de 2000.

[18] "Evolução da Participação dos Estados no ICMS Brasileiro"; "Evolução da Participação dos Estados no PIB Brasileiro". Seção Brasil P. 14. Folha de São Paulo, ano 80, № 25.890: São Paulo, 20 de fevereiro de 2000.

[19] BAHIA. Governo do Estado da Bahia. Relatório de Atividades de 1991 - Mensagem do Governador. Salvador-Ba, fevereiro de 1992, p. VII.

[20] Liberdade para Crescer. In: Federação das Indústrias do Estado da Bahia - FIEB. Boletim Industrial. Salvador-Ba, v. 26, $\mathrm{n}^{\circ} 415$, dez. 1991, p. 5.

[21] Visto em uma perspectiva de funcionalidade sistêmica, tanto os capitalistas do CentroSul quanto os do Estado da Bahia passariam a fazer parte de uma mesma relação de elevação da competitivdade, quando ambos realizam ao seu modo a adequação possível ao movimento atual de acumulação do Capital. Mas, como essa relação não é uniforme, nem necessariamente os ganhos finais do processo, que tendem a se concentrar no lócus do pólo mais poderoso, teríamos assim em meio à Sociedade Competitiva o seu pólo subordinado. O Estado da Bahia exerceria assim o papel de sociedade competitiva subordinada em relação ao Capital que se relocaliza.

[22] Segundo Lopes e Rodrigues, que escreviam nos anos 60, relações de produção e relações industriais (esse último termo é usado por Lopes) modernas seriam aquelas onde há presença do sindicato, de legislação trabalhista mais efetiva, e de certa organização classista ou sócio-profissional por parte dos trabalhadores. Essas características na sociedade brasileira configurariam a crise de relações tradicionais que, por seu turno, dificultavam a elevação da produtividade industrial. Essa crise seria a modernização das relações de produção representativas do "pólo arcaico" da sociedade brasileira, ou seja, aquelas áreas distantes dos centros urbano-industriais. Não temos na contemporaneidade essa tendência de linearidade na concentração do "moderno" nos locais mais ligados ao mundo urbano-industrial (Regiões Metropolitanas) e de industrialização mais antiga. Hoje essa definição é borrada pela tendência do Capital buscar o "arcaico" para se atualizar, para torna-se mais competitivo. Temos assim, por exemplo, grandes empresas se instalando nos recônditos do Nordeste, no interior da Bahia, a cerca de $500 \mathrm{Km}$ de Salvador. Isso porque o "moderno" torna-se cada vez mais insuportável para o Capital frente às novas demandas de acumulação. Por um lado, combinam-se assim técnicas extremamente contemporâneas com o retrocesso a relações de assalariamento e de produção que lembram o século XIX, por outro lado, em tempos ditos pós-modernos, essas sínteses aparente "assincrônicas" são extremanente atuais. Sobre o debate entre o "moderno" e o "arcaico" na industrialização brasileira ver: LOPES, Juarez R. B. Crise no Brasil Arcaico. São Paulo-SP: Difusão Européia do Livro, 1967; RODRIGUES, Leôcio Martins. Industrialização e Atitudes Operárias: estudo de um grupo de trabalhadores. São Paulo-SP: Editora Brasiliense, 1970. Sobre a "condição pós-moderna", Ver: HARVEY, David. Condição Pós-Moderna. São Paulo-SP: Edições Loyola, 1992; JAMENSON, 
Fredric. Pós-modernismo: a lógica cultural do capitalismo tardio. São Paulo-SP: Editora Ática.

[23] BAHIA. Governo do Estado da Bahia. Relatório de Atividades de 1991. Secretaria da Indústria, Comércio e Turismo. Salvador-Ba, fevereiro de 1992, p. 103.

[24] Ibidem, p. IV

[25] No Brasil, o Estado sempre teve uma forte presença empresarial, criando importantes empresas (a Petrobrás e a Vale do Rio Doce são exemplos clássicos) em setores cujo capital nacional não lograva condições tecnológicas e montante de recursos que viabilizassem sua atuação. Usamos o termo "lógica empresarial-privatista" para expressar um fenômeno recente de privatização do Estado: a penetração do ethos empresarialprivatista na aparelhagem estatal. Assim, até o ethos das empresas citadas tendem a ser despublicizado quando estas são, por exemplo, privatizadas.

[26] É Preciso Mudar o Estado In: Federação das Indústrias do Estado da Bahia - FIEB. Boletim Industrial. Salvador-Ba, ano I, $n^{\circ}$ 3, maio de 1993, p. 1.

[27] O "Custo Brasil" simboliza, para os empresários, um conjunto de elementos que oneram a produção industrial e por sua vez comprometem a competitividade do setor. Dentre eles se encontrariam conquistas sociais do trabalhador e os impostos cobrados pelo Estado. A CNI tomou então a iniciativa de discutir com o Congresso Nacional os projetos de lei que se encaminham na direção da redução desses "custos". Como parte dessa estratégia as federações estaduais também elaboraram algo parecido, daí a discussão em torno do "Custo Bahia". Ver: CNI - Confederação Nacional da Indústria. Custo Brasil: agenda no Congresso Nacional. Rio de Janeiro-RJ: CNI, 1996.

[28] Conferência Ibero-Americana. Desenvolvimento Exige Erradicação da Pobreza. In: Federação das Indústrias do Estado da Bahia - FIEB. Boletim Industrial. Salvador-Ba, ano I, $\mathrm{n}^{\circ} 7$, julho de 1993, p. 9.

[29] BAHIA. Governo do Estado da Bahia. Relatório de Atividades de 1991 - Mensagem do Governador. Salvador-Ba, fevereiro de 1992, P V.

[30] Com o advento do capitalismo monopolista o atendimento às carências perderia esse sentido. As demandas sociais se transformariam em um ex-ante necessário à reprodução ampliada do capital. Atualmente ainda é importante, mas a apropriação do fundo público se dá cada vez mais diretamente pelo Capital, sem muita mediação. Certamente a relação que aponto se revelaria inconseqüente, por exemplo, nos anos 60 ou 70, mas não quando se levam em conta o movimento atual de redirecionamento e privatização do fundo público. Mais profundamente, levando-se em conta o próprio processo civilizatório, verificase então um fenômeno de institucionalização de uma versão ampliada do facismo territorial do capital, que segundo Boaventura Santos seria uma vertente do facismo paraestatal; na Bahia o facismo paraestatal em sua vertente territorial vai se institucionalizando aos poucos. A redefinição competitivista subordinada do Estado mostra aqui uma de suas faces trágicas para as populações mais afastadas das esferas do poder. Ver: SANTOS, Boaventura de Souza. Reinvetar a Democracia. In: HELLER, Agnes [et alli ]. A Crise dos Paradigmas em Ciências sociais e os Demais desafios para o Século XXI. Rio de Janeiro-RJ: Contraponto, 1999, p. 52-53.

[31] Vale mencionar que, em suas atividades como técnico na aparelhagem estatal, Paulo Souto sempre esteve próximo dos empresários, seja como Superintendente da SUDENE, seja como Secretário da Indústria e Comércio durante o Governo ACM. Os componentes 
da equipe do Governo ACM se revezariam no poder nas duas gestões seguintes com Paulo Souto e César Borges.

[32] Paulo Souto Anuncia Metas para a Indústria In: Federação das Indústrias do Estado da Bahia - FIEB. BAHIAINDÚSTRIA. Salvador-Ba, ano I, n 12, dez. de 1993, p. 4.

[33]BAHIA. Governo do Estado da Bahia. Relatório de Atividades de 1995-1997. Salvador, fevereiro de 1995, P. 9.

[34]BAHIA. Governo do Estado da Bahia. Relatório de Atividades de 1996. Mensagem do Governador. Salvador-Ba, março de 1997, P. IV-V. Em janeiro de 1997 o Governo sistematizaria esses princípios com a aprovação do Programa de Incentivo às Organizações Sociais - PROGERIR.

[35] BAHIA. Governo do Estado da Bahia. Organizações Sociais. Apresentação.

Salvador-Ba, 08/11/2000 (buscar em:

WWW.bahia.ba.gov.br/saeb/oRSociais/p_recurso.htm)

[36] Ibidem, idem.

[37] Ibidem, (buscar em: WWW.bahia.ba.gov.br/saeb/oRSociais/p_acomp.htm)

[38]FRIEDMAN, Milton. Capitalismo e Liberdade. Coleção Os Economistas. 3a Ed. São Paulo-SP: Nova Cultural, 1988.

[39] BAHIA. Governo do Estado da Bahia. Organizações Sociais. Apresentação.

Salvador-Ba, 08/11/2000, p.1. (buscar em:

WWW.bahia.ba.gov.br/saeb/oRSociais/p_apresent.htm)

[40] BAHIA. Governo do Estado da Bahia. Relatório de Atividades de 1995-1997.

Salvador-Ba, fevereiro de 1998, P. 12-13.

[41] Ibidem, p. 12-13.

[42] PEREIRA, Luiz Carlos Bresser. Plano Diretor da Reforma do Aparelho do Estado. Administração Pública. Brasília-DF: Editora Brasil LTDA, 1996. p. 90.

[43] Fruto das relações de poder presentes na sociedade, as forças sociais com maior poder de organizar e articular suas propostas com as de outros segmentos sociais tendem a obter uma maior vantagem quanto a realização de suas estratégias em nível global, metamorfoseando não só aparelhagem estatal, mas também as relações sociais à "sua imagem e semelhança". Isso pode ser comprovado na própria definição do que é desenvolvimento social e de como se pode alcançá-lo.

[44]BAHIA. Governo do Estado da Bahia. Relatório de Atividades de 1996. Mensagem do Governador. Salvador-Ba, março de 1997, P. IV.

[45]BAHIA. Governo do Estado da Bahia. Relatório de Atividades de 1995-1997. Salvador, fevereiro de 1995, P. 8.

[46] Bandeira de Mello é especialista em administração pública e direito público, professor titular de Direito Administrativo da PUC-SP, esteve na FIEB participando do Seminário sobre Direito Econômico e Empresarial. Entrevista: "Aparelho Estatal é Ineficiente". In: 
Federação das Indústrias do Estado da Bahia - FIEB. BAHIAINDÚSTRIA. Salvador-Ba, ano III, $\mathrm{n}^{\circ} 36$, dez. de 1995, P. 7.

[47] Federação das Indústrias do Estado da Bahia - FIEB. BAHIAINDÚSTRIA. SalvadorBa, ano IV, $\mathrm{n}^{\circ} 40$, abril. de 1996, p. 7.

[48] FRIEDMAN, Op. Cit.

[49] Federação das Indústrias do Estado da Bahia - FIEB. Departamento de Economia. Industrialização na Bahia: construindo uma nova estratégia. Salvador-Ba, 1995.

[50] Rumo ao Desenvolvimento. In: Federação das Indústrias do Estado da Bahia - FIEB. Boletim Industrial. Salvador-Ba, ano III, n³6, dez. de 1995, p. 3-4.

[51] lbidem, p. 4.

[52] Ibidem, p. 5.

[53] Federação das Indústrias do Estado da Bahia - FIEB. Programa Estratégico de Desenvolvimento Industrial do Estado da Bahia. Salvador-Ba: FIEB/SEI, 1998 [SEI Superintendência de Estudos Econômicos e Sociais da Bahia, órgão estadual vinculado à Secretaria de Ciência e Tecnologia - SEPLANTEC], p. 8

[54] Cf: RODRIGUES, José. O Moderno Príncipe Industrial: o pensamento pedagógico da Confederação Nacional da Indústria. Campinas-SP: Autores Associados, 1998.

[55] Federação das Indústrias do Estado da Bahia - FIEB. Programa Estratégico de Desenvolvimento Industrial do Estado da Bahia. Salvador-BA: FIEB/SEI, 1998 [SEI Superintendência de Estudos Econômicos e Sociais da Bahia, órgão estadual vinculado à Secretaria de Ciência e Tecnologia - SEPLANTEC], p. 8.

[56] Federação das Indústrias do Estado da Bahia - FIEB. BAHIAINDÚSTRIA. SalvadorBa, ano VIII, $\mathrm{n}^{\circ} 88$, abril de 1999, p. 9.

[57] Cf: MARX, Karl. Salário, Preço e Lucro. In: MARX, Karl \& ENGELS, Friedrich. Obras Escolhidas. São Paulo-SP: Alfa-Ômega, 1986.

\section{volta}

